\title{
The Development of the Corpus Callosum in the Healthy Human Brain
}

\author{
Eileen Luders, Paul M. Thompson, Arthur W. Toga \\ Laboratory of Neuro Imaging, Department of Neurology, University of California, Los Angeles, School of Medicine, Los Angeles, California 90095-7334
}

The corpus callosum changes structurally throughout life, but most dramatically during childhood and adolescence. Even so, existing studies of callosal development tend to use parcellation schemes that may not capture the complex spatial profile of anatomical changes. Thus, more detailed mapping of callosal growth processes is desirable to create a normative reference. This will help to relate and interpret other structural, functional, and behavioral measurements, both from healthy subjects and pediatric patients. We applied computational surface-based mesh-modeling methods to analyze callosal morphology at extremely high spatial resolution. We mapped callosal development and explored sex differences in a large and well matched sample of healthy children and adolescents $(n=190)$ aged 5-18 years. Except for the rostrum in females, callosal thickness increased across the whole surface, with sex- and region-specific rates of growth, and at times shrinkage. The temporally distinct changes in callosal thickness are likely to be a consequence of varying degrees of axonal myelination, redirection, and pruning. Alternating phases of callosal growth and shrinkage may reflect a permanent adjustment and fine-tuning of fibers connecting homologous cortical areas during childhood and adolescence. Our findings emphasize the importance of taking into account sex differences in future studies, as existing developmental effects might remain disguised (or biased toward the effect of the dominant sex in unbalanced statistical designs) when pooling male and female samples.

\section{Introduction}

The corpus callosum is the largest interhemispheric commissure, consisting of $>200$ million fibers connecting the two brain hemispheres. The number of callosal fibers is already fixed around birth, but structural changes of the corpus callosum continue to occur during postnatal development due to fiber myelination, redirection, and pruning. Prior studies in children and adolescents revealed trends for more pronounced growth in posterior versus anterior callosal sections (Giedd et al., 1996, 1997, 1999; Rajapakse et al., 1996; Thompson et al., 2000; Chung et al., 2001) and larger increases in males compared with females, but not all reports are consistent (Allen et al., 1991; Giedd et al., 1996, 1997, 1999; Rajapakse et al., 1996; De Bellis et al., 2001; Lenroot et al., 2007; Hasan et al., 2008). Discrepancies across studies may be due to samples of varying sizes and compositions (e.g., with respect to the age and sex of subjects included) and different methods to

\footnotetext{
Received Oct. 13, 2009; revised June 16, 2010; accepted June 19, 2010.

This work was supported by the National Institutes of Health (NIH) Grants P41 RR013642, R01 EB008281, M01 RR000865, and EB007813, and through the NIH Roadmap for Medical Research, Grant U54 RR021813, entitled Center for Computational Biology. Scans used in this article were obtained from the Pediatric MRI Data Repository created by the NIH MRI Study of Normal Brain Development. This is a multisite, Iongitudinal study of typically developing children, from newborns to young adults, conducted by the Brain Development Cooperative Group and supported by the National Institute of Child Health and Human Development, the National Institute on Drug Abuse, the National Institute of Mental Health, and the National Institute of Neurological Disorders and Stroke (Contracts N01-HD02-3343, N01-MH9-0002, and N01-NS-9-2314,-2315,-2316,-2317,-2319, and -2320). P.M.T. is also supported by NIH Grants AG016570, EB01651, LM05639, and RR019771. We thank Boris Gutman and Alen Zamanyan for their assistance in preprocessing image data. This manuscript reflects the views of the authors and may not reflect the opinions or views of the NIH.

Correspondence should be addressed to Dr. Arthur W. Toga, Laboratory of Neuro Imaging, Department of Neurology, University of California, Los Angeles, School of Medicine, 635 Charles Young Drive South, Suite 225, Los Angeles, CA 90095-7334. E-mail: toga@loni.ucla.edu.

DOI:10.1523/JNEUROSC1.5122-09.2010

Copyright $\odot 2010$ the authors $\quad 0270-6474 / 10 / 3010985-06 \$ 15.00 / 0$
}

quantify callosal changes. More specifically, prior analyses often defined callosal sectors according to parcellation schemes which, although well established (Witelson, 1989), have recently generated some controversy (Hofer and Frahm, 2006; Tomaiuolo et al., 2007) and lack the necessary spatial detail to capture callosal maturation in its full spatial and temporal complexity. Thompson et al. (2000) used continuum mechanical tensor maps to visualize local profiles of growth rates and repeatedly scanned children across time spans of up to four years. Although this longitudinal study revealed callosal growth maps with great spatial detail, it only examined a very small number of children $(n=$ $5)$. Another deformation-based longitudinal study with a larger sample $(n=28)$ also observed localized growth of the corpus callosum, but sex differences were not examined (Chung et al., 2001). Clearly, there is a lack of comprehensive reference data with respect to callosal maturation. However, detailed sexspecific normative data on developmental profiles is vital to help relate and interpret behavioral, functional, and structural data from healthy subjects and in children with neuropsychiatric disorders that may involve abnormal interhemispheric integration (Giedd et al., 1996). Thus, in the current study, we mapped callosal development at an extremely high spatial resolution in a large and well matched sample of 95 male and 95 female subjects between the ages of 5 and 18 years. The overarching goal of this work was to provide reference data reflecting the sex-specific development of the corpus callosum in great detail.

\section{Materials and Methods}

Subjects. All subjects were selected from a database pertaining to the First Objective of the MRI Study of Normal Brain Development (Brain Development Cooperative Group and Evans, 2006). Subjects were excluded if they met criteria that "are established or highly suspected to adversely 
Table 1. Number of subjects per age and within merged age groups

\begin{tabular}{llll}
\hline $\begin{array}{l}\text { Number in combined } \\
\text { sample (M/F) }\end{array}$ & $\begin{array}{l}\text { Ages } \\
\text { (years) }\end{array}$ & $\begin{array}{l}\text { Merged age } \\
\text { groups }\end{array}$ & $\begin{array}{l}\text { Number in combined } \\
\text { sample (M/F) }\end{array}$ \\
\hline $6(3 / 3)$ & 5 & & $16(8 / 8)$ \\
$10(5 / 5)$ & 6 & Group 1 & $36(18 / 18)$ \\
$20(10 / 10)$ & 7 & Group 2 & \\
$16(8 / 8)$ & 8 & & $30(15 / 15)$ \\
$12(6 / 6)$ & 9 & Group 3 & $36(18 / 18)$ \\
$18(9 / 9)$ & 10 & & \\
$12(6 / 6)$ & 11 & Group 4 & $34(17 / 17)$ \\
$24(12 / 12)$ & 12 & Group 5 & \\
$18(9 / 9)$ & 13 & & $20(10 / 10)$ \\
$16(8 / 8)$ & 14 & Group 6 & $18(9 / 9)$ \\
$8(4 / 4)$ & 15 & & Group 7 \\
$12(6 / 6)$ & 16 & & \\
$12(6 / 6)$ & 17 & 18 &
\end{tabular}

M, Males; F, females

impact healthy brain development," detailed previously (Brain Development Cooperative Group and Evans, 2006). The final sample of the current study $(n=190)$ included 95 males and 95 females, ranging between 5 and 18 years of age (mean \pm SD, $11.31 \pm 3.54$ years). Males and females were carefully matched for age (Table 1 ). To determine handedness in children younger than 6 years, subjects were asked to perform 10 different activities, modified from the Edinburgh Handedness Inventory (EHI) (Oldfield, 1971). Activities were rated as right-handed (RH), lefthanded ( $\mathrm{LH})$, or bimanual $(\mathrm{BM})$, then the Bimanual Laterality Index (BLI) (Michel et al., 1985) was calculated using the following formula: (number of $\mathrm{RH}-$ [number of $\mathrm{LH}+$ number of $\mathrm{BM}]$ ) divided by the square root of (number of $\mathrm{RH}+$ number of $\mathrm{LH}+$ number of $\mathrm{BM})$. Based on the resulting BLI, subjects were categorized as right handers (BLI $>$ $+1)$, left handers (BLI $<-1)$, or mixed handers $(-1 \leq \mathrm{BLI} \geq+1)$. To determine handedness in subjects aged 6 years and older, subjects were ask to perform eight different activities, modified from the EHI. RH activities were rated with $1 ; \mathrm{LH}$ activities were rated with 0 . Subjects with total scores of 7-8 were classified as right-handers, subject with total scores of $<7$ were classified as non-right-handers. The sample of the current study contained 166 right-handers ( 83 males; 83 females) and 23 non-right-handers (12 males; 11 females). Handedness information for one female subject was missing. Informed consent was obtained from parents and adult subjects, and assents were obtained from the children. All protocols and procedures were approved by the relevant institutional review board at each pediatric study center and at each coordinating center (Brain Development Cooperative Group and Evans, 2006).

Image acquisition. Images were obtained on $1.5 \mathrm{~T}$ systems from GE Healthcare or Siemens Medical Systems using a three-dimensional T1weighted spoiled gradient recalled (SPGR) echo sequence with the following parameters: repetition time, 22-25 ms; echo time, $10-11 \mathrm{~ms}$; excitation pulse, $30^{\circ}$; refocusing pulse, $180^{\circ}$; orientation, sagittal; field of view: anterior-posterior, $256 \mathrm{~mm}$; left-right, $160-180 \mathrm{~mm}$ (whole head coverage), voxel size, $1 \mathrm{~mm}^{3}$, where the maximum number of slices on GE scanners was 124, and hence the slice thickness was increased to 1.5 mm (Brain Development Cooperative Group and Evans, 2006).

Preprocessing. We applied automated radiofrequency-bias field corrections to correct image volumes for intensity drifts caused by magnetic field inhomogeneities (Shattuck et al., 2001). In addition, we placed all images volumes into a standard coordinate system by coregistering them to the ICBM-152 template using automated six-parameter rigid-body transformations (Woods et al., 1998). This procedure corrects for differences in brain alignment between subjects, whereas individual differences in brain size and shape are preserved (i.e., images were reoriented but not scaled or warped). The corpus callosum was then outlined automatically based on the Chan-Vese model for active contours (Chan and Vese, 2001) using the LONI pipeline processing environment (Rex et al., 2003). This resulted in two midsagittal callosal segments (i.e., the upper and lower callosal boundary) for each subject, as detailed previously (Luders et al., 2006). Subsequently, each callosal segment was overlaid onto the respective individual anatomical image and visually inspected to insure that generated outlines followed precisely the natural course and boundaries of the corpus callosum.

Callosal thickness measurement. To obtain highly localized measures of callosal thickness, anatomical surface-based mesh-modeling methods were used (Thompson et al., 1996a,b). That is, the randomly digitized points making up the upper and lower callosal boundary were redigitized to render them spatially uniform. Subsequently, a new segment (i.e., the medial core) was automatically created by calculating a spatial average two-dimensional curve from 100 equidistant surface points representing the upper and lower callosal boundaries. Finally, the distances between 100 surface points of the medial core and the 100 corresponding surface points of the upper/lower callosal boundaries were automatically quantified. These regional distances indicated callosal thickness with a high spatial resolution (i.e., at 100 locations distributed evenly over the callosal surface).

Statistical analyses. We mapped the correlations between age and callosal thickness (i.e., the callosal distance measures) at 100 equidistant surface points. Furthermore, we mapped callosal thickness differences between the youngest group (5- to 6-year-olds) and the oldest group (17to 18-year-olds). These correlations and group comparisons were conducted on the entire combined sample, as well as within groups of females and males separately. In addition, we tested for possible interactions with sex. For this purpose, we analyzed which callosal regions showed significant differences in the slopes of the sex-specific regression lines and where comparing the youngest with the oldest group revealed significantly different effects in males and females. For all these analyses, an uncorrected two-tailed $\alpha$ level of $p \leq 0.05$ was determined as the threshold for projecting significance values $(p)$ onto the group-averaged callosal surface models. In addition, we generated callosal maps corrected for multiple comparisons using false discovery rate (FDR) thresholded at 0.05 (Benjamini and Hochberg, 1995).

Temporally distinct changes. To visualize callosal growth in different epochs, we reduced the 14 age groups to seven age groups, each covering two years (Table 1). Then we mapped the callosal thickness in group 1 (i.e., the average callosal thickness at 5-6 years). Subsequently, we mapped the increase in callosal thickness in groups 2-7 as compared with group 1 (absolute growth). In addition, we mapped callosal thickness differences between consecutive age groups (relative growth). Maps indicating absolute growth and relative growth were generated separately for males and females.

Possible effects of handedness. To address whether the subsample of 23 subjects classified as non-right-handers might bias the study outcomes, we recalculated the correlations between age and callosal thickness while excluding the non-right-handers. In addition, we mapped significant callosal thickness differences between the 23 non-right-handers and a carefully selected subsample of 23 right-handers, pairwise matched with respect to sex and age.

\section{Results}

\section{Significant correlations between callosal thickness and age}

As shown in Figure 1, within the combined sample we detected significant positive correlations between callosal thickness and age (ranging from 5 to 18 years) across the entire posterior surface of the corpus callosum, spanning the splenium, isthmus, and posterior midbody. For the sake of clarity, although our analyses were not based on traditional parcellation schemes, we will describe our findings by referring to well known vertical callosal segments (Witelson, 1989), as shown in Figure 2. We also observed significant positive correlations across the anterior surface, including the anterior midbody (posterior part) and the anterior third (genu). All these regions remained significant at $q=0.03$ (the $q$-value is the FDR analog of the $p$-value) when corrections for multiple comparisons using FDR were applied. Significant negative correlations were revealed near the tip of the anterior third (rostrum); however, these did not survive FDR correction.

We discovered a similar significance profile when analyzing correlations within females, where positive correlations survived 


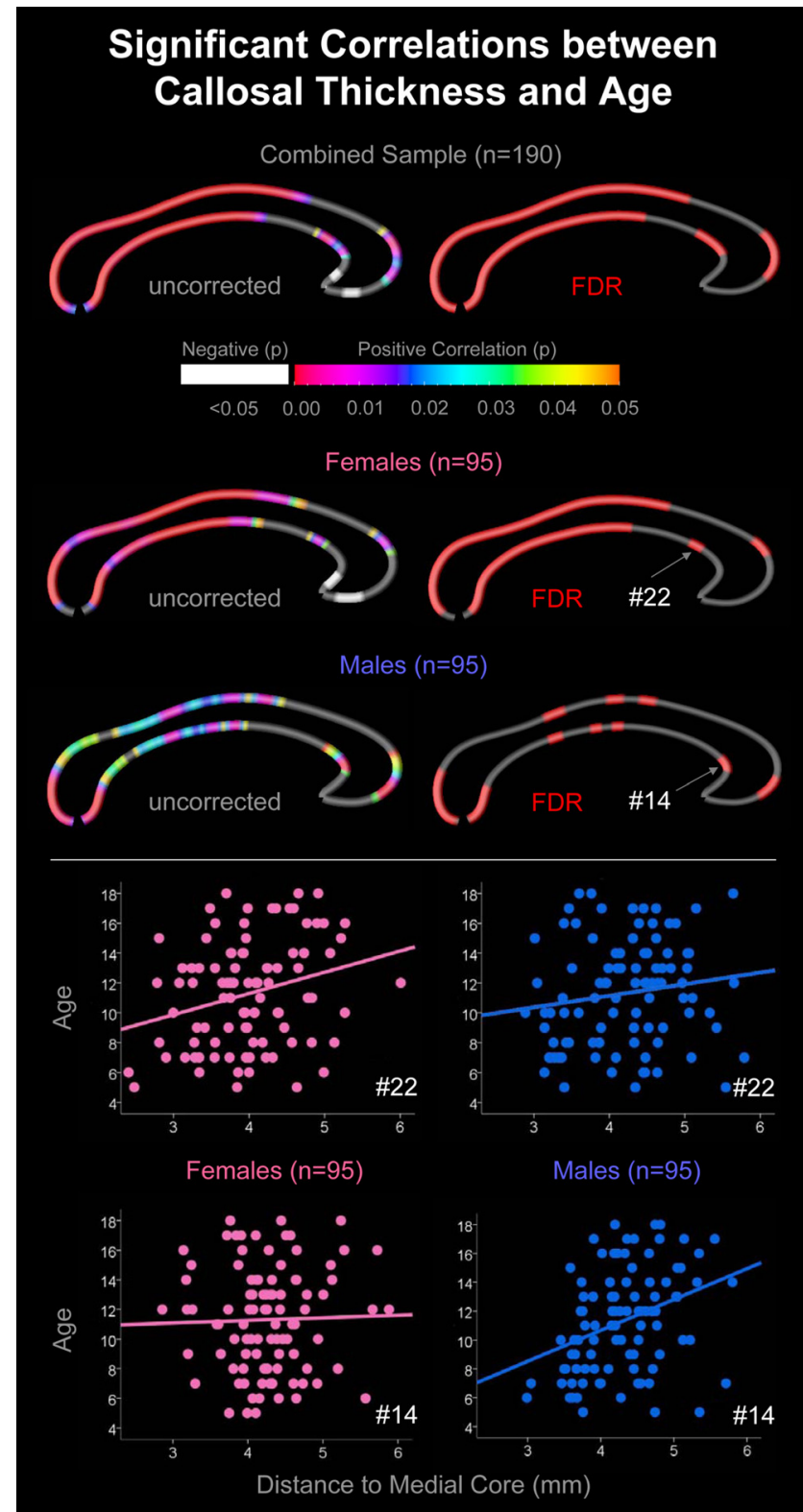

Figure 1. Significant correlations between callosal thickness and age across the ages 5-18 years. Top, left, The color bar encodes the uncorrected significance $(p)$ of positive correlations. White regions indicate significant negative correlations. Top, right, Callosal maps indicate in red where significant correlations survived FDR-corrections. Bottom, Scatter plots illustrate examples of sex-specific correlations at the most significant callosal surface point within the anterior third in females (point no. 22) and in males (point no. 14).

FDR corrections at $q=0.02$ but negative correlations did not. Although significant negative correlations were completely absent in males, callosal sections showing significant positive correlations were similar to those in females, but fewer regions survived FDR correction in males at $q=0.01$. Moreover, the positive correlations in the anterior third in males (most significant point, no. $14 ; p=0.0005$ ) were located inferior to the ones detected within females (most significant point, no. $22 ; p=$ 0.008). The scatterplots in Figure 1 illustrate sex-specific correlations at these most significant callosal surface points.

\section{Significant differences in callosal thickness between the} youngest and the oldest group

As shown in Figure 3, comparing the youngest subjects (5- to 6-year-olds) to the oldest subjects (17-to 18-year-olds), the most

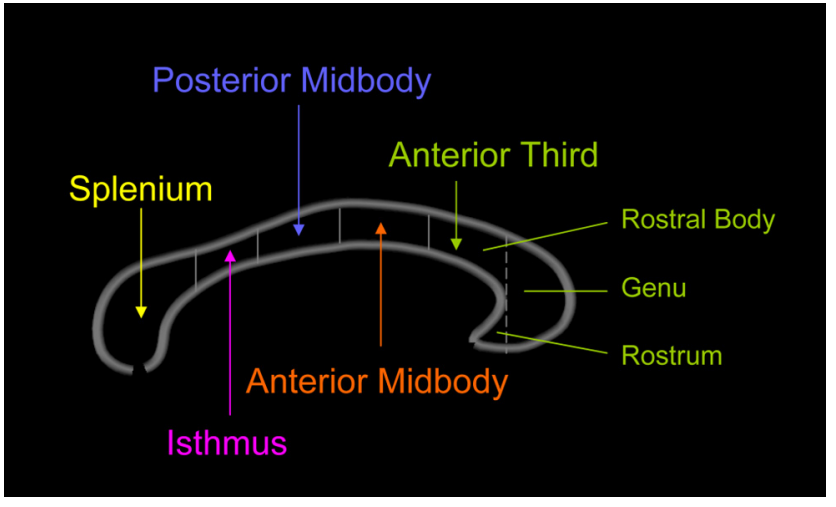

Figure 2. Definition of callosal subregions. Visualized are callosal segments according to the Witelson parcellation scheme (Witelson, 1989).

significant callosal growth was detected in the splenium and posterior midbody. These findings survived FDR correction within the whole group and within females at $q=0.01$. Significant regions were less spatially extended in males, but we also detected increases in the splenium and callosal midbody. Interestingly, females showed pronounced increases in the posterior midbody but the increase in males was slightly shifted toward the anterior midbody. In addition, males displayed significant increases in the anterior third (genu), whereas females displayed a significant decrease in the rostrum. However, none of these effects survived FDR correction in males. Thus, the scatterplots in Figure 3 provide examples of sex-specific callosal thickness at the two most significant callosal surface points within females (point no. 58 , $p=0.0004$; point no. 92, $p=0.0008$ ).

Finally, when we tested for possible interactions with sex (both with respect to the correlation between callosal thickness and age and the differences between the youngest and oldest subjects), we revealed significant sex effects in the posterior and anterior midbody and in the genu. However, these effects did not survive FDR correction (data not shown).

\section{Temporally distinct changes}

As shown in Figure 4, top, the thickness of the corpus callosum was similar in females and males at age 5-6 years. The maximum callosal thickness of $8-10 \mathrm{~mm}$ (i.e., $4-5 \mathrm{~mm}$ distance from the upper/lower boundary to the medial core) was located in the splenium and anterior third (genu). As further demonstrated in Figure 4 (rows A-F), callosal thickness increased over time with larger increases in posterior than anterior sections. The maximum growth of $2.2 \mathrm{~mm}$ (i.e., $1.1 \mathrm{~mm}$ distance from the upper/ lower boundary to the medial core) was detected in the splenium (in females and males), the posterior and anterior midbody (in females), and the rostrum (in males). Interestingly, callosal thickness was smaller at age 17-18 years than at age 5-6 years within the rostrum (in females), isthmus (in males), and rostral body (in males). Decreases in the isthmus were also apparent in females at age 17-18 years, but its absolute size was still larger than at age 5-6 years. The rostrum, which was already decreased early in development (at age 7-8 years in females and 9-10 years in males), started increasing again in males at age 17-18 years. Supplemental Figure 1 (available at www.jneurosci.org as supplemental material) provides an additional overview of sex-specific callosal changes between consecutive age groups (relative growth). As illustrated, callosal thickness increased over time across the whole surface (but also decreased at times), with different growth spurts in different epochs and different growth 


\section{Significant Differences between Youngest and Oldest Group}

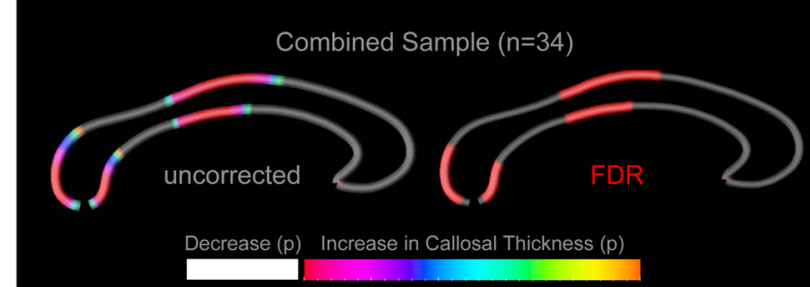

$\begin{array}{lllllll}<.05 & 0.00 & 0.01 & 0.02 & 0.03 & 0.04 & 0.05\end{array}$

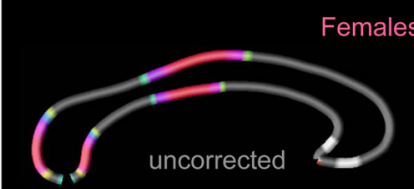

emales $(n=17)$

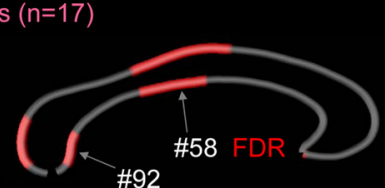

\#92

Males $(n=17)$
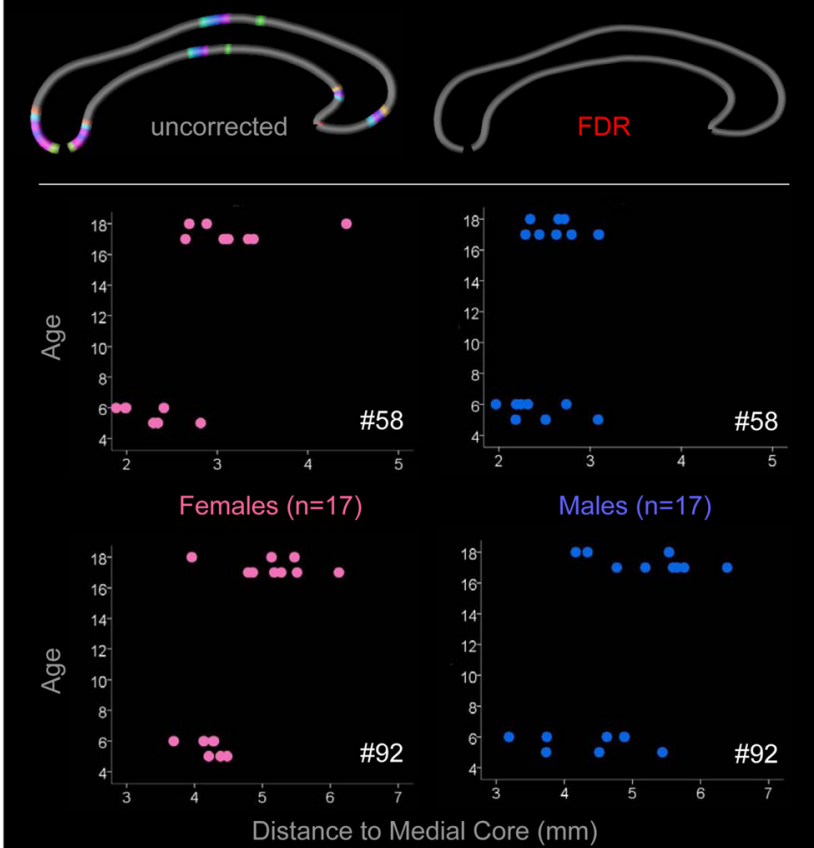

Distance to Medial Core $(\mathrm{mm})$

Figure 3. Significant differences in callosal thickness between youngest group (5- to 6-yearolds) and oldest group (17- to 18-year-olds). Top, left, The color bar encodes the uncorrected significance $(p)$ of callosal increase. White regions indicate significant decrease. Top, right, Callosal maps indicate in red where significant group differences survived FDR-corrections. Bottom, Scatter plots illustrate examples of sex-specific callosal thickness at the two most significant callosal surface points within females (point nos. 58 and 92).

profiles in males and females. For example, within the isthmus, we detected the initial callosal growth spurt in girls at age 9-10 years. Increases at the isthmus in boys (although less pronounced) became apparent at age 11-12 years. In both boys and girls, parts of the callosal isthmus continue to grow until the age of 15-16 years before the whole isthmus starts decreasing at age $17-18$ years.

\section{Handedness effects}

Excluding the subsample of 23 non-right-handers did not alter the significance profile of the correlation between age and callosal thickness (supplemental Fig. 2, left panel, available at www. jneurosci.org as supplemental material). Also, callosal morphology did not differ significantly between the carefully matched 23 non-right-handers and 23 right-handers (supplemental Fig. 2, right panel, available at www.jneurosci.org as supplemental material). These outcomes agree closely with previous findings suggesting that handedness effects are rather negligible when assessing brain structure in pediatric samples (Wilke et al., 2008).

\section{Discussion}

We mapped callosal development in a large sample of children and adolescents aged 5-18 years. Callosal development involves horizontal and vertical changes, but conclusions about development in the present study refer to the vertical dimension (callosal thickness). Callosal maturation patterns differed between females and males and were strikingly variable across different callosal sections. Callosal growth was detected across almost the whole surface (except for the female rostrum) with sex- and region-specific rates of increase, and at times decreases. Since the number of callosal fibers is already determined around birth increases in callosal thickness are likely to reflect increases in fiber myelination, whereas decreases in callosal thickness may be associated with axonal redirection and pruning (Galaburda et al., 1990; Luo and O'Leary, 2005). Alternating phases of callosal growth and shrinkage may reflect a permanent adjustment and fine-tuning of fibers connecting homologous cortical areas during childhood and adolescence.

\section{Maturation gradients}

Positive correlations between age and callosal thickness were more pronounced in posterior than anterior sections (Fig. 1). The posterior dominance was confirmed when comparing the youngest with the oldest group (Fig. 3) and when mapping absolute changes in callosal thickness (Fig. 4). These outcomes agree with reports of greater age-related changes in posterior regions than in anterior regions in subjects aged 4-18 years (Giedd et al., 1996, 1997, 1999; Rajapakse et al., 1996), 7-22 years (Chung et al., 2001), and 6-15 years (Thompson et al., 2000). Interestingly, when measuring the corpus callosum in 3- to 6-year-olds, the latter study revealed the most pronounced growth in anterior sections. Thompson et al. (2000) suggested a rostrocaudal wave of callosal development between ages 3 to 15 years, possibly mirroring the callosal maturation pattern from early embryonic stages to term (Rakic and Yakovlev, 1968). Our findings complement the hypothesis of an anterior-to-posterior maturation gradient and advocate the age of 9-10 (in girls) and 11-12 (in boys) years as a critical period where callosal growth in posterior sections starts to dominate over growth in anterior sections (supplemental Fig. 1, available at www.jneurosci.org as supplemental material). As further illustrated (supplemental Fig. 1), toward the end of childhood the developmental profile appears to undergo another switch with more pronounced growth in anterior sections starting at age 15-16 (in girls) and 17-18 (in boys) years. This may reconcile a paradox in earlier work: in several reports, there appeared to be a forward-moving wave of maturation in which the frontal and temporal lobes had a more protracted period of development with peak volumes for these lobes occurring later in adolescence than for parietal and occipital lobes (Sowell et al., 1999, 2001; Gogtay et al., 2004; Gogtay and Thompson, 2010). Although this late frontal development led to theoretical and empirical support for the relative immaturity and vulnerability of the frontal lobes in adolescence, it was not readily reconciled with a wave of growth in the corpus callosum that appeared to move backwards toward the isthmus and splenium around the age of puberty (Thompson et al., 2000; Chung et al., 2001). Our new findings suggest that there may be growth in anterior callosal 


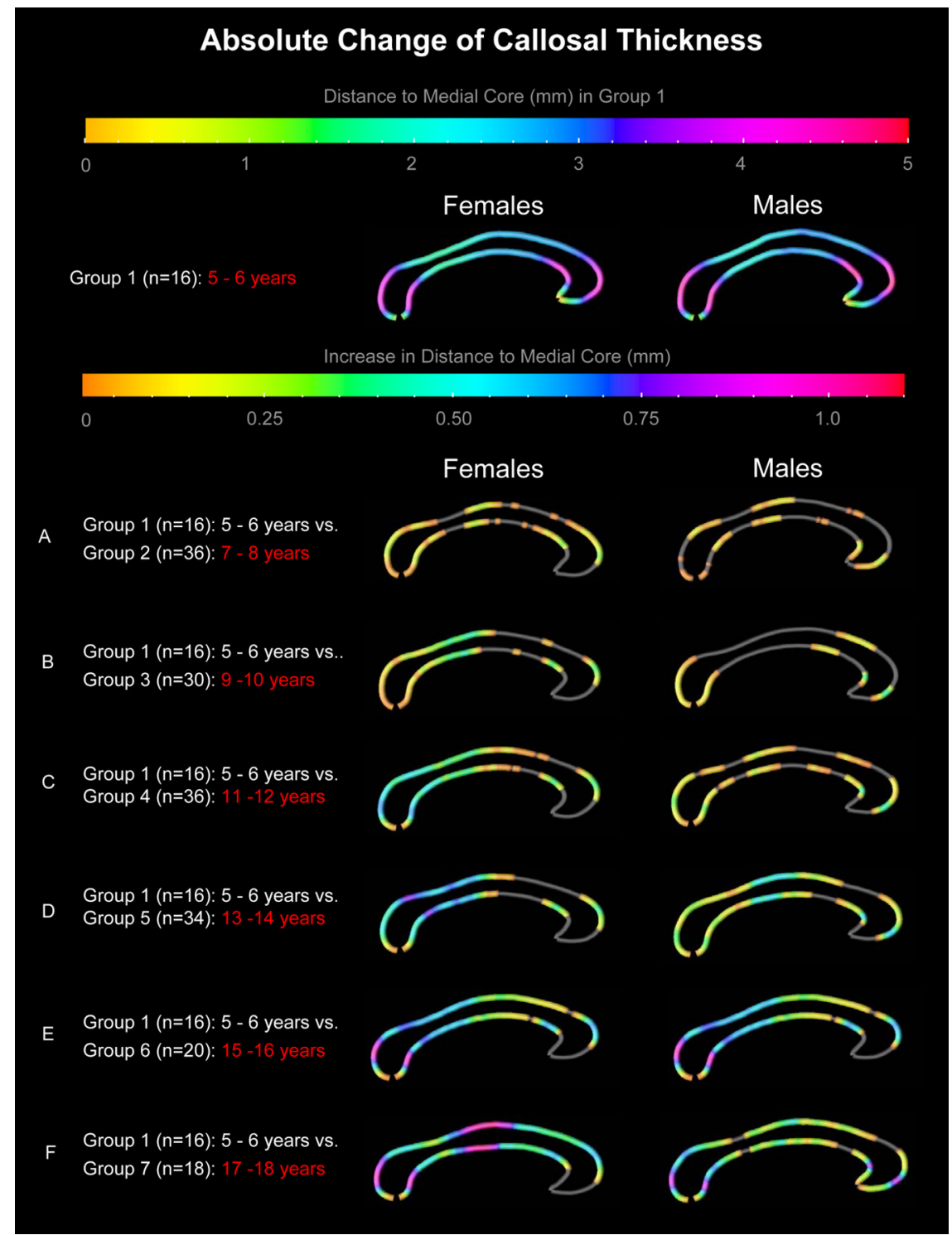

Figure 4. Absolute change of callosal thickness. Top, Average callosal thickness in group 1 (age 5-6 years). The color bar indicates the distance from the upper/lower callosal boundaries to the medial core with the maximum at $5 \mathrm{~mm}$. Rows A-F display the absolute change in callosal thickness over time (i.e., compared with group 1). The color bar encodes the increase in distance to the medial core with the maximum at $1.1 \mathrm{~mm}$. Gray regions indicate no change or a decrease.

sections in later adolescence at a time when the frontal lobes actively develop.

Our observed positive correlations between age and callosal thickness in the genu (Fig. 1) disagree with previous reports of similar midsagittal area measures of the genu in children and adults (Giedd et al., 1996). These contrasting results may be due to different callosal measurements if prior area-based approaches lacked the regional specificity necessary to detect differences.

\section{Sex-specific developments}

Significant correlations between callosal thickness and age and group differences between the youngest and oldest subjects are found in analogous regions in both sexes across the posterior callosal surface but were more pronounced in females (Figs. 1, 3). This contrasts with reports of similar (or larger) growth in boys for global white matter volumes (Reiss et al., 1996; De Bellis et al., 2001; Wilke et al., 2007) and total midsagittal callosal areas (De Bellis et al., 2001; Lenroot et al., 2007). Other analyses based on segment-specific callosal area measures revealed similar growth rates in both sexes (Giedd et al., 1996, 1997, 1999; Rajapakse et al., 1996). These contrasting results may be due to the high regional specificity of the current approach, which captures extremely local characteristics by computing a pointwise indicator of callosal thickness with submillimeter accuracy. Nonetheless, in agreement with our findings, Giedd et al. (1997) reported that females showed a steeper slope (10.1 $\mathrm{mm}^{2} /$ year) than males $\left(7.1 \mathrm{~mm}^{2} /\right.$ year $)$. Surprisingly, another study by Allen et al. (1991) detected greater increases in boys than girls, which might be due to their sample composition (12 matched pairs of 2-15 year-olds), which is not fully comparable to the current sample (95 matched pairs of 5-18 year-olds). It is possible that callosal growth is more pronounced in boys during early childhood, but slows down in boys and/or accelerates in girls later. This hypothesis warrants testing in samples younger than 5 years.

Sex-specific developments also became obvious when considering absolute and relative callosal growth (Fig. 4 and supplemental Fig. 1, available at www. jneurosci.org as supplemental material). For example, within the isthmus, we detected the initial callosal growth spurt in girls at age 9-10 years. Increases at the isthmus in boys (although less pronounced) became apparent at age 11-12 years. The isthmus primarily contains fibers mediating information exchange between parietal and temporal lobes (Hofer and Frahm, 2006; Park et al., 2008). Thus, the observed maturation delay in boys agrees with gray matter volume peaks in temporal and parietal regions occurring 1-2 years later in boys than in girls (Lenroot et al., 2007). An accelerated isthmus growth suggests the development of networks supporting associative reasoning and language functions after children enter school (albeit not immediately when formal education starts). Peak growth occurring before the age of 13 years supports the hypothesis "that there is a critical period for firstlanguage acquisition that ends at puberty, if not before" (Grimshaw et al., 1998). The continuing growth of the callosal isthmus, up until the age of 15-16 years, agrees with previously reported growth foci in linguistic callosal regions in subjects aged 6-15 years (Thompson et al., 2000) and may reflect fine tuning of language functions known to occur late in childhood. Finally, at age 17-18 years, the isthmus starts decreasing, possibly due to pruning of fibers that connect auditory and speech systems. Any pruning might indicate a decreased interhemispheric communication, perhaps due to language functions being more lateralized at age 17-18 years than before. This assumption agrees with outcomes from functional analyses indicating that language lateralization increases between 5 and 20 years, plateaus between 20 and 25 years, and slowly decreases between 25 and 70 years (Szaflarski 
et al., 2006). Albeit intriguing, these sex-specific developmental profiles require replication in larger subsamples with sufficient statistical power. Such replication may also reveal whether, for example, the callosal rostrum is truly decreasing early in development (e.g., at age 7-8 years in females and at age 9-10 years in males), and if it increases again at age 17-18 years, perhaps only in males, as suggested by the current study.

\section{Future directions}

The overarching goal of this work was to provide sex-specific reference data detailing the development of the corpus callosum based on cross-sectional MRI data from healthy subjects aged 5-18 years. This will help to relate and interpret other structural, functional, and behavioral measurements, both from healthy subjects and pediatric patients. Future studies will expand this line of research by focusing on different ages or even the entire lifespan, by combining cross-sectional and longitudinal research, and by complementing indicators of callosal macrostructure with descriptors of callosal microstructure, possibly based on diffusion tensor imaging (Hasan et al., 2008, 2009).

\section{References}

Allen LS, Richey MF, Chai YM, Gorski RA (1991) Sex differences in the corpus callosum of the living human being. J Neurosci 11:933-942.

Benjamini Y, Hochberg Y (1995) Controlling the false discovery rate: a pratical and powerful approach to multiple testing. J R Stat Soc 57:289-300.

Brain Development Cooperative Group, Evans AC (2006) The NIH MRI study of normal brain development. Neuroimage 30:184-202.

Chan TF, Vese LA (2001) Active contours without edges. IEEE Trans Image Process 10:266-277.

Chung MK, Worsley KJ, Paus T, Cherif C, Collins DL, Giedd JN, Rapoport JL, Evans AC (2001) A unified statistical approach to deformation-based morphometry. Neuroimage 14:595-606.

De Bellis MD, Keshavan MS, Beers SR, Hall J, Frustaci K, Masalehdan A, Noll J, Boring AM (2001) Sex differences in brain maturation during childhood and adolescence. Cereb Cortex 11:552-557.

Galaburda AM, Rosen GD, Sherman GF (1990) Individual variability in cortical organization: its relationship to brain laterality and implications to function. Neuropsychologia 28:529-546.

Giedd JN, Rumsey JM, Castellanos FX, Rajapakse JC, Kaysen D, Vaituzis AC, Vauss YC, Hamburger SD, Rapoport JL (1996) A quantitative MRI study of the corpus callosum in children and adolescents. Brain Res Dev Brain Res 91:274-280.

Giedd JN, Castellanos FX, Rajapakse JC, Vaituzis AC, Rapoport JL (1997) Sexual dimorphism of the developing human brain. Prog Neuropsychopharmacol Biol Psychiatry 21:1185-1201.

Giedd JN, Blumenthal J, Jeffries NO, Rajapakse JC, Vaituzis AC, Liu H, Berry YC, Tobin M, Nelson J, Castellanos FX (1999) Development of the human corpus callosum during childhood and adolescence: a longitudinal MRI study. Prog Neuropsychopharmacol Biol Psychiatry 23:571-588.

Gogtay N, Thompson PM (2010) Mapping gray matter development: implications for typical development and vulnerability to psychopathology. Brain Cogn 72:6-15.

Gogtay N, Giedd JN, Lusk L, Hayashi KM, Greenstein D, Vaituzis AC, Nugent TF 3rd, Herman DH, Clasen LS, Toga AW, Rapoport JL, Thompson PM (2004) Dynamic mapping of human cortical development during childhood through early adulthood. Proc Natl Acad Sci U S A 101:8174-8179.

Grimshaw GM, Adelstein A, Bryden MP, MacKinnon GE (1998) Firstlanguage acquisition in adolescence: evidence for a critical period for verbal language development. Brain Lang 63:237-255.

Hasan KM, Kamali A, Kramer LA, Papnicolaou AC, Fletcher JM, Ewing-Cobbs L (2008) Diffusion tensor quantification of the human midsagittal corpus callosum subdivisions across the lifespan. Brain Res 1227:52-67.

Hasan KM, Kamali A, Iftikhar A, Kramer LA, Papanicolaou AC, Fletcher JM, Ewing-Cobbs L (2009) Diffusion tensor tractography quantification of the human corpus callosum fiber pathways across the lifespan. Brain Res 1249:91-100.

Hofer S, Frahm J (2006) Topography of the human corpus callosum revisited: comprehensive fiber tractography using diffusion tensor magnetic resonance imaging. Neuroimage 32:989-994.

Lenroot RK, Gogtay N, Greenstein DK, Wells EM, Wallace GL, Clasen LS, Blumenthal JD, Lerch J, Zijdenbos AP, Evans AC, Thompson PM, Giedd JN (2007) Sexual dimorphism of brain developmental trajectories during childhood and adolescence. Neuroimage 36:1065-1073.

Luders E, Narr KL, Zaidel E, Thompson PM, Jancke L, Toga AW (2006) Parasagittal asymmetries of the corpus callosum. Cereb Cortex 16:346-354.

Luo L, O'Leary DD (2005) Axon retraction and degeneration in development and disease. Annu Rev Neurosci 28:127-156.

Michel GF, Ovrut MR, Harkins DA (1985) Hand-use preference for reaching and object manipulation in 6- through 13-month-old infants. Genet Soc Gen Psychol Monogr 111:407-427.

Oldfield RC (1971) The assessment and analysis of handedness: the Edinburgh inventory. Neuropsychologia 9:97-113.

Park HJ, Kim JJ, Lee SK, Seok JH, Chun J, Kim DI, Lee JD (2008) Corpus callosal connection mapping using cortical gray matter parcellation and DT-MRI. Hum Brain Mapp 29:503-516.

Rajapakse JC, Giedd JN, Rumsey JM, Vaituzis AC, Hamburger SD, Rapoport JL (1996) Regional MRI measurements of the corpus callosum: a methodological and developmental study. Brain Dev 18:379-388.

Rakic P, Yakovlev PI (1968) Development of the corpus callosum and cavum septi in man. J Comp Neurol 132:45-72.

Reiss AL, Abrams MT, Singer HS, Ross JL, Denckla MB (1996) Brain development, gender and IQ in children: a volumetric imaging study. Brain 119:1763-1774.

Rex DE, Ma JQ, Toga AW (2003) The LONI pipeline processing environment. Neuroimage 19:1033-1048.

Shattuck DW, Sandor-Leahy SR, Schaper KA, Rottenberg DA, Leahy RM (2001) Magnetic resonance image tissue classification using a partial volume model. Neuroimage 13:856-876.

Sowell ER, Thompson PM, Holmes CJ, Jernigan TL, Toga AW (1999) In vivo evidence for post-adolescent brain maturation in frontal and striatal regions. Nat Neurosci 2:859-861.

Sowell ER, Thompson PM, Tessner KD, Toga AW (2001) Mapping continued brain growth and gray matter density reduction in dorsal frontal cortex: inverse relationships during postadolescent brain maturation. J Neurosci 21:8819-8829.

Szaflarski JP, Holland SK, Schmithorst VJ, Byars AW (2006) fMRI study of language lateralization in children and adults. Hum Brain Mapp 27:202-212.

Thompson PM, Schwartz C, Lin RT, Khan AA, Toga AW (1996a) Threedimensional statistical analysis of sulcal variability in the human brain. J Neurosci 16:4261-4274.

Thompson PM, Schwartz C, Toga AW (1996b) High-resolution random mesh algorithms for creating a probabilistic 3D surface atlas of the human brain. Neuroimage 3:19-34.

Thompson PM, Giedd JN, Woods RP, MacDonald D, Evans AC, Toga AW (2000) Growth patterns in the developing brain detected by using continuum mechanical tensor maps. Nature 404:190-193.

Tomaiuolo F, Scapin M, Di Paola M, Le Nezet P, Fadda L, Musicco M, Caltagirone C, Collins DL (2007) Gross anatomy of the corpus callosum in Alzheimer's disease: regions of degeneration and their neuropsychological correlates. Dement Geriatr Cogn Disord 23:96-103.

Wilke M, Krägeloh-Mann I, Holland SK (2007) Global and local development of gray and white matter volume in normal children and adolescents. Exp Brain Res 178:296-307.

Wilke M, Holland SK, Altaye M, Gaser C (2008) Template-O-Matic: a toolbox for creating customized pediatric templates. Neuroimage 41:903-913.

Witelson SF (1989) Hand and sex differences in the isthmus and genu of the human corpus callosum: a postmortem morphological study. Brain 112:799-835.

Woods RP, Grafton ST, Watson JD, Sicotte NL, Mazziotta JC (1998) Automated image registration. II. Intersubject validation of linear and nonlinear models. J Comput Assist Tomogr 22:153-165. 